\title{
Ego, Convolution, and Exchange: Reflections on Modern Chinese Aesthetics*
}

\author{
ZHAO Zhen \\ Xiamen University, Fujian, China \\ Zunyi Normal College, Guizhou, China
}

\begin{abstract}
Contemporary Chinese aesthetics have three important "traces": ego aesthetics represented by Chinese fantasy literature; convoluted aesthetics represented by the contemporary Chinese movie "Loss” and the novel Monk; and the fetish aesthetics of symbolic exchange, as represented by Huang Xiaoming's wedding and the auctioning of Jack Ma's painting. These represent the transmutation of contemporary Chinese aesthetics from adolescent ego aesthetics to adult convoluted aesthetics to the fetish aesthetics of symbolic exchange, thus completing the successive change of logic from ego to society to reality. In tracing these successive changes in logic, we are thinking about questions raised by the times. These concern the future of Chinese contemporary aesthetics and constitute an aesthetic revolution. They mean that contemporary Chinese aesthetic practice has moved from text to community and then evolved into social reality. Further, they also smack of mutual imitation between aesthetics and life. Contemporary Chinese theorists should be actively involved in the revolution, responding to major issues and, as they face social practices, acquiring transcendental characteristics in contemporary aesthetic leadership.
\end{abstract}

Keywords: ego, convolution, imagination, tragedy, modernity, exchange, symbol

During the twentieth century, unprecedented changes took place in the human world, especially in culture. If we borrow the concept of the magnitude of "cultural seismology" from British literary theorists James McFarlane and Mc Bruitbly to describe these changes, they would undoubtedly rank as amounting to a third-magnitude quake capable of overturning everything: "Those displacements, those cultural disasters, and those fundamental commotions caused by the creative human spirit-they overturned the most stable and solid things in our beliefs and ideas and razed the vast area of the past into rubble. They doubted all of civilization or culture and then made another insane comeback. This is what we call a third-magnitude earthquake."1

For aesthetics, these broke and abandoned Kant's distinctions of beauty and liberated aesthetics from its confinement: "From Marxism to Postmodernism, an important direction in modern aesthetics has been, since Kant, to attack the concept of the self-discipline of art and aesthetic independence. Arts certainly cannot exceed

\footnotetext{
* Acknowledgements: This paper was sponsored by China National Social Science Foundation "Research on the Fundamental Problems of the Contemporary Aesthetics and Criticism Patterns" (15ZDB023) and the National Social Science Fund Project "Chinese 'Fantasy Literature' Studied in the Western Cultural Context” (11XZW031).

ZHAO Zhen is a doctoral candidate in Xiamen University and a professor in Zunyi Normal College.

${ }^{1}$ Chiefly edited by Liu Xiangyu, Yang Hengda, and Zeng Yanbing, From Modernism to Postmodernism, Beijing: Higher Education Press, 2006, p. 25.
} 
social life, and aesthetic appreciation is not a purely mental activity."2 This was an aesthetic revolution with negative and positive dimensions, and Adorno saw the negative dimension: "Ironically, Socrates' proposition that 'beauty is useful' has finally been realized today.”3 Justin O’Connor sees a positive dimension: “'Art' and modern capitalism appear almost simultaneously, and art and modern capitalism are both a series of unique practices with completely changing social trends resulting from the divisive modernity of our lives.”4 More importantly, the production of art involves the reproduction of so-called cultural values, and in the broadest sense cultural values refer to the productivity and serviceability of their values. We categorize this sense into traditions, customs, regulation, beliefs, public meaning, shareable group identity, communication practices, etc. In short, it is 'the entirety of a lifestyle.",5

If the production of modern art is seen as the reproduction of "the entirety of a lifestyle," then it involves the reproduction of "cosmic order." So-called "cosmic order" refers to the act in human existence of constructing values based on both the real world and the beyond, thus providing us with a "world picture" and "value system." It can be said that human history is a continuous process of remodeling the "cosmic order" in which we see a personal world corresponding to the "world picture," and the relationship between these can be viewed as the "relationship between the macro-universe and the micro-universe." Ancient Greek culture called this relationship "topos," "the cosmological model (the celestial sphere-the Earth) believed by the Greeks.” The "cosmic order" and the individual order are identical and each mirrors the other. From individual order you can see "cosmic order" or "historical order," and you can also find changes and the reconstruction process of the cosmic order or the historical order beginning from the individual order. This is because "The subject, according to signs of external things that he himself projects in his feeling, creates the world outside him: the identity of things keeping in complicated features and conditions. At the same time, he learns to recognize both the comprehensive unity of external impression and the inner impression manner that moves away from the outer impression, constructing 'ego' in memorizing. The real ego is the final product of projection... This distinction occurs in the subject, but the subject has put the outside world into his own consciousness and at the same time recognized it as something else. Therefore, reflection, this rational life, is produced as a conscious projection." In other words, subjective self-consciousness reflects order in the external world, analysis of subjective self-consciousness can help us understand external order, and self-conscious reflection can help us grasp consciousness and the world. We can say that self-consciousness is the bridge connecting the world and the ego, and we can understand one by understanding and grasping the other. The world is the projection of self-consciousness, and starting from self-consciousness is probably the best way. At the same time, considering that literary work is the result of a concentrated expression of self-consciousness, literature relying on its sensitivity can keenly grasp changes in social ideas, thereby becoming a revolutionary forerunner of aesthetics. I intend to start from the unique and controversial "fantasy literature" in contemporary Chinese

\footnotetext{
2 Shan Shilian, The Dark Moment: Hitler, the Holocaust and Nazi Culture (Volume one), Guangzhou: Guangdong People Publishing House, 2015, p. 392.

${ }^{3}$ [Germany] Max Horkheimer and Theodor Adorno, Dialectics of Enlightenment: Philosophical Fragments, translated by Qu Jingdong, Cao Weidong, Shanghai: Shanghai People Publishing House, 2006, p. 141.

${ }^{4}$ [Britain] Justin O’Connor, Art and the Creative Industries, translated by Wang Bin, Zhang Liangcong, Beijing: Central Compilation and Translation Press, 2013, p. 27.

${ }^{5}$ [Britain] Justin O’Connor, Art and Creative Industries, p. 185.

6 TS Kuhn, The Copernican Revolution, Harvard University Press, 1979, chap.1, quoted in Wu Guosheng: The Greek Concept of Space, Beijing: Renmin University Press, 2010, p. 9.

7 [Germany] Max Horkheimer and Theodor Adorno, Dialectics of Enlightenment: Philosophical Fragments, p. 174.
} 
literature and examine three important levels of Chinese contemporary aesthetics that constitute a logical evolution of the important "traces" in Chinese contemporary aesthetics—ego, society, and reality—and thereby show a picture of the contemporary Chinese aesthetic spirit.

\section{First, Fantasy Literature: Ego Representation}

Fantasy literature is a form of literature with Chinese characteristics. Its appearance is not an accident but a necessity, and its characteristics and the reasons for its emergence have not yet been effectively explained. “Fantasy literature” comes from “fantasy novels.” According to Ye Yonglie, “'Fantasy novels,' as far as I know, come from Hong Kong. The earliest fantasy novel I saw was Huang Yi’s Moon Magic, published in 1988 by Hong Kong's Juxian Press. At that time Juxian Press was also preparing to publish my work, and its publisher, Mr. Zhao Shanqi, gave me a novel by the Hong Kong writer Huang Yi. Mr. Zhao Shanqi wrote in the preface, 'The birth of a new kind of metaphysics combining science and literature is announced, and we call this kind of novel 'fantasy magic fiction.' This was the debut of the word 'fantasy,' and it had a clear definition.”8 Since its appearance, fantasy literature has been an object of obsession, especially among teenagers. Mr. Tao Dongfeng thinks that "'Fantasy literature' is the cynicism of the times and that the indication that the value of fantasy literature is upside down, in chaos, and full to the brim in identifying with practical logic." One scholar believes that "Contemporary online fantasy fiction explores humanity in the form of fantasy." Legend of Chusen tries to describe love, whether the short and tangled family love between Zhang Xiaofan and Pu Zhi; the blood family love of the couple Tian Buyi and Zhang Xiaofan; the simple and complicated love of Tian Ling'er for Zhang Xiaofan; the loyal love of Bi Yao for Zhang Xiaofan, when the former falls in love with the latter at first sight and gives her life for the survival of her lover; the on-again, off-again, life-and-death love of Lu Xueqi for Zhang Xiaofan; the frank and persistent friendship of Lin Jingyu with Zhang Xiaofan; or even how Therion, who has committed heinous crimes and insists on thousands of years of practice just for a woman named Ling Long and is willing to abandon his only immortal body to stay with his beloved forever-the descriptions of every kind of love all make people feel and sense the goodness and complexity of human nature." ${ }^{10}$ Another researcher also believes that "Fantasy literature, as a new literary style, subverts wild ambition and courage in traditional values and constructs a second world of creativity with its unrestrained imagination All of this is remarkable, but the unorganized and messy features in its values reflect paralysis and the collapse of the humanistic spirit, and it is indeed worrisome."11

Fantasy literature is a special form of literature, and its appearance is no accident. On the one hand, we see its current popularity in China and its "liberating" function on the imagination, and on the other hand we should see that features of fantasy literature itself have not been precisely grasped and that no further exploration has been conducted into the reasons for the appearance of fantasy literature. So many arguments are mere discoveries that lack demonstrative substantiation, and this makes us unable to grasp its essence, let alone examine its evolutionary logic based on its very essence. Therefore, I explore features of fantasy literature and discover ecology and order in contemporary Chinese culture. I believe that Chinese fantasy literature has three main features, as below.

\footnotetext{
${ }^{8}$ Ye Yonglie, Xuanhuan Fever, Fantasy Fever, and Science Fiction Literature, China Reading Weekly, 14th Edition, July $27^{\text {th }}$, 2005.

9 See Tao Dongfeng, Fantasy Literature: Cynicism of the Times, China Reading Weekly, 9th Edition, June 21st, 2006.

${ }^{10} \mathrm{Li} \mathrm{Ru}$ and Wang Zongfa, On the Impact of the Ghost Stories in Ming Dynasty on Contemporary Online Fantasy Novels, Study on Novels in Ming and Qing Dynasties, third issue, 2014.

11 Zhang Guolong, 2000-2010 Studies on the Chinese Children's Literature Phenomenon, Dongyue Tribune, ninth issue, 2011.
} 


\section{Disorder and Blending of Imagination}

Imagination in fantasy literature is eclectic and fanciful, to some extent, and of course it plays a role in the liberation of the imagination. But it is undeniable that disorder and blending of imagination in Chinese fantasy literature is quite special, as Tao Dongfeng points out: "Fantasy literature is not only free from the constraints of physical laws in the natural world, rational rules in the social world, and common sense rules in everyday life, but completely reverses these specifications." ${ }^{12}$ Xu Wenjun puts it more clearly: "Fantasy fiction can be said to be fantasy novels with Chinese characteristics. The principle of its creation is without principles, and the basis of its fantasy is without basis. It is so inclusive that any external matters can be melded into it and some new things derived from it. Most fantasy novels take Western magic, Chinese martial arts and strategy, and Japanese character models and link these with science fiction and myth (and Chinese, Indian, and Greek myths often coexist) to build a magical world and a wonderful story. A blending of anime, computer games, and literature along with the increasing popularity of Western fantasy movies in recent years has directly contributed to its popularity. Many popular fantasy novels are mainly a blending of magic and knights in Western fantasy novels as protagonists along with defiant fighting spirit, exaggerated and amusing gimmicks, upgraded games, war and intrigue, and some selling points of pornography, all thrown in together with the world outlook and philosophy of life as taught in politics and history textbooks in middle school."13 This blending of a variety of knowledge and superficial knowledgeability is in fact an arbitrary blending of various fragments of knowledge. It is worth noting that even in the direct source of fantasy literature, which is Western magic literature (as represented by The Lord of the Rings and Harry Potter), certainty and presentation are not as random and willful as in they are in fantasy literature and comply with a certain internal logic. As Lin Guoji has pointed out, "Plotinus's mystical experience does not come from a chaotic epiphany or wild thinking, but follows a strict sequence. This experience has a strong speculative color, and from it we can see the profound impact of ancient Greek philosophy on him. This is also the common feature of Western mysticism, and it cannot be ignored." 14

Strict logic and inherent sequence are qualities of Western mysticism and Western fantasy literature, and they can be said to be testimonies to human civilization and progress. Just as Cassirer has pointed out in Mythology, the difference between sorcerous thinking and scientific thinking is this: "Scientific thinking re-shows its dual characteristics while assuming similarities and constructing the same series; synthesis and analysis proceed at the same time. It emphasizes both dissimilar and similar factors in the same context, and in fact it attaches particular importance to dissimilar factors because in determining its species and genera, it is more concerned about principles of distinction and classification in the same species than in the common elements indicated in species and genera." ${ }^{15}$ Therefore replacing sorcery with science was progress for humankind. When we examine Western magic literary works (The Lord of the Rings, Harry Potter, and so on), we find that they are based on the completion of modernity, which they re-think and criticize, and these actions

\footnotetext{
12 Tao Dongfeng, Youth Literature, Fantasy Literature and Grave Raid Literature-The Generation After 1980s Writing Highlights, Journal of China University of Political Science and Law, fifth issue, 2008.

${ }_{13}$ Xu Wenjun, On “Fantasy” Fiction among Online Literatures, Master Dissertation, Inner Mongolia Normal University, 2012, pp. $1-2$.

${ }^{14}$ Lin Guoji, Social Contract Theory Tradition in Theodicy Context, Shanghai: Shanghai Joint Publishing Corporation, 2005, p. 31.

${ }^{15}$ [Germany] Ernst Cassirer, Mythological Thinking, translated by Huang Longbao and Zhou Zhenxuan, Beijing: China Social Sciences Publishing House, 1992, p. 76.
} 
themselves are in turn based on modernity. Chinese fantasy literature has appeared during the process of China's unfolding modernity, with the result that just when modernity as represented by scientific thinking was being established, it was washed away by premodern intellectual trends. Meanwhile, because Chinese modernity is incomplete, the constant influx of Western post-modern thought will lead to the blending or overlapping of Chinese modernity, pre-modernity, and post-modernity. Under these circumstances, many varieties of opposite or even diametrically opposed knowledge will be formed simultaneously, so of course knowledge will be half digested and have apparent but superficial compatibility, while in reality it will simply be fragments of knowledge or superficial understanding all jumbled together, resulting in a superficially rich "knowledge" that actually conceals its own superficiality and want of imagination.

\section{Lack of Humanity}

Chinese fantasy literature has appeared in the process of Chinese modernity and its dual contexts, namely traditional cultural context and the context of modernity, and it lacks both a deep understanding of humanity and regard for it. This has resulted in an inborn shortness and postnatal maladjustment. Regarding the traditional context, the "human being" is missing in Chinese traditional culture, where the human being does not appear with the image of an independent individual capable of self-reflection. On the contrary, the human being is defined by groups and is subordinate to the collective, so to some extent we can say that traditional Chinese culture is "others-oriented" rather than "self-oriented." In such a culture, it is only natural that the modern individual cannot develop. At the same time there is the particularity of Chinese modernity: "The basic characteristics of Chinese modernity are external and posterior. The so-called 'external' indicates that that Chinese modernity is not the product of local culture but was introduced from the West, thus triggering enduring cultural conflicts. The so-called 'posterior' indicates that Chinese modernity lags behind the original modernity of the West, draws ideological resources from Western modernity, and develops them inadequately." ${ }^{\prime 16}$ More troublesome still is the continual influx of Western postmodernism brought in by globalism. In some ways, postmodernism has dispelled an already-weak modern culture of individuality, thus putting the modern subject in its moment of tentativeness in danger of deconstruction.

Chinese fantasy literature appeared against this background, so it is difficult for this literature to generate regard for humanity and deep insight into it. This in turn has determined that it cannot possess or generate its own independent spiritual dimension. When a literature or culture itself cannot generate a self-sufficient spiritual dimension, it is bound to find some kind of external spiritual dimension to support it, and this is the case with Chinese fantasy literature. It is difficult for fantasy literature itself to produce a self-sufficient spiritual dimension, and it is also bound to find its own value dimension in the outside world and identify with the dominant mainstream culture. No wonder then that Chinese fantasy literature refers to and imitates Western fantasy literature. It can be said that the strength of Western culture and the exquisiteness of Western fantasy literature give Chinese fantasy literature good reason to value and recognize it. But at the same time, the realization of any recognition process must be based on the original ego. In other words, pre-existent ego is a recognized prior structure that provides the means for determining how to recognize foreign culture: What to recognize, what to exclude, and what to recognize to what degree. It must start from its own traditions to look for some kind of "affinity," and for Chinese fantasy literature this "affinity” is like "winner takes all” logic and unprincipled recognition of power and money in traditional culture. Therefore, fantasy literature achieves the

${ }^{16}$ Yang Chunshi, Modernity and Chinese Literary Trends, Beijing: SDX Joint Publishing Corporation, 2009, p. 269. 
superposition of dual validity, that is, "relying on foreign forces" and "being based on ancient statues." Therefore the mentality of the old Q-style "I do not care Who's Who" and overweening conceit abound all the more.

It is worth noting that the situation in Chinese fantasy literature described above is strengthened by how China is realizing modernity while promoting two logics, as pointed out by British scholar Gerald Delanty: “A logic of modernity, namely the fight between capitalism and democracy in the Western world, leads to movement from organized modernity to post-modernity (post-modernity still is within the scope of modernity); while another logic, that is modernity promoted by country, not only suppresses democracy, but also capitalism, resulting in totalitarianism (totalitarianism must be viewed as another face of modernity). In the former logic, cultural modernity retains some traditions of bourgeois and Christian; in the latter logic, pre-modern and modern traditions are almost all destroyed." ${ }^{17}$ There is no doubt that Chinese modernity belongs to the latter logic, which means that the destructiveness of modernity on traditional culture has deprived China of a corresponding cultural basis of support and constraints. As Horkheimer and Adorno have criticized trenchantly, "Thinking objectifies itself into an involuntary self-driven process, into an embodiment of a machine; the machine is formed in this process so that finally thought can be completely replaced by the machine."18 One of the consequences of modernity is the objectification of subject, which ultimately results in measuring the human condition by materials, which in turn is alienation of people. Traditional culture in the process of China's modernity cannot provide for the restraint of adverse consequences of modernity, and this has filled Chinese society with a taste for the "money fetishism" that Marx criticized. Many people get caught up in this taste. Under such circumstances, the lack of personal spiritual transcendence in Chinese fantasy literature, when coupled with China's cultural industry, leads to the continuous recognition and strengthening of practical social authority and the logic of money. From the fabricated, made-up world of fantasy literature are obtained the self-importance, arrogance, and mad confusion of overweening conceit.

If we also take into account an important source of Chinese fantasy literature, this fact will be even clearer: "The creative way of modern Western fantasy, such as DND fiction, is already closely associated with role-playing games. The two are rather similar in the process of construction work and the preparation process for stage backgrounds and props. The rules and logic for setting the process in the virtual world are quite similar to game rules. Unfolding the plot and pushing the story forward against the finished stage background and rules, the writer on the one hand can experience the rhythm and direction of self-control and, on the other, happily enjoy variable adventure while readers will be surprised as if they were exploring a new fantasy world." ${ }^{19}$ In online games, if we want to win we must treat people as numbers and objects. In any online game we must treat the "enemy" as the means instead of the end. Once we have tender regard for people as an end, it would be impossible for online games involving killing to continue. As affected by online games (DND novels), the already very rarefied spiritual dimensions of Chinese fantasy literature become much thinner and more fragile.

The above reasons make it difficult for Chinese fantasy literature to have tender human regard and transcendence over the real world, and the inevitable logic is nothing but the unprincipled logic of recognizing reality. Although it is powerful, it has no values and no tender human regard!

\footnotetext{
${ }^{17}$ [Britain] Gerard Delanty, Modernity and Post Modernity: Knowledge, Power and Self, translated by Li Ruihua, Preface and Acknowledgements, Beijing: Commercial Press, 2012, p. 4.

${ }_{18}$ [Germany] Max Horkheimer and Theodor Adorno. Dialectics of Enlightenment: Philosophical Fragments, p. 19.

19 Gong Yanan, Studies on Contemporary Chinese Fantasy Fiction, Master Dissertation, Suzhou University, 2009, pp. 39-40.
} 


\section{Adolescent Writers and Readers}

Fantasy literature is an online literature, the writers and readers of which are mostly in adolescence. It is therefore adolescent writing, but the particularity of its writers and readers makes this adolescent literature more special. First, as for the writers, Wang Shu points out that "Writers of online novels are mainly youth and mostly have academic backgrounds in science." ${ }^{20} \mathrm{Xu}$ Wenjun points out more particularly, "The writers of current fantasy novels are basically young men between 20 and 30 years of age, and their generation has read Jin Yong's novels and has been influenced by martial arts movies. Most of them study science and engineering and have liked watching cartoons and playing computer games since childhood. The collision of dreamy childhood knight culture and cartoon culture fosters their love of writing fantasy novels online for fun, and their novels themselves have the nature of games."21 The cultural literacy of this group is not high; their science and engineering backgrounds and the separation of liberal arts and science in Chinese exam-oriented education has deprived them of sufficient humanistic literacy, and they fundamentally lack human concern. To some extent their creations are for "warming themselves" with literature as they engage in increasingly cold and boring scientific thinking. Literature helps them escape cold reality with beautiful memories of the past. Meanwhile, because there was no modern science in traditional Chinese culture, the banner of science that flew high during the May Fourth Period caused people to come up with a mindset or ideology that upholds science as omnipotent. Of this Hu Shi once said, "In the last three decades, a noun has almost been put into a supreme position in the nation. Whether people understand it or not, whether conservatives or reformists are afraid to openly express contempt for it or not, this word is science. ${ }^{, 2}$ The supreme ideological nature of science exists up to the present, and therefore many fantasy literature writers believe that they can destroy all of literature in the name of science. Some even conduct pseudo-scientific activities in the name of science. The writers of Chinese fantasy literature believe science to be omnipotent, and with their backgrounds in science and engineering they apply the omnipotence of science to fantasy literature writing. Some of them are quite self-willed and harbor fantasies of conquering the world of literature when in fact they have nothing at all but empty ego behind them. Only people with nothing at all will adorn themselves with fragmentary knowledge of the past and present, of China and the outside world.

Writers of Chinese fantasy literature use adolescent rebellion to resist reality. When they display hurt and ego, they are leading off with emotion and escape, which in turn is suitable for adolescent audiences. As they enter into adolescence they will engage in adolescent rebellion, such as deconstruction and parody of the traditional mainstream culture, but their experience, knowledge, and many other aspects of life are not sufficient for them to fully deconstruct the mainstream cultural order. They therefore can only demonstrate their individual existences through local subversion, parody, ridicule, and distortion of mainstream culture. To some extent, fantasy literature satisfies the demands of adolescents and unpleasant people to escape social reality, and in fantasy literature they can redeem the ego they lost in the world of reality. The combination of fantasy literature and modern technology introduces the fantasy world of pure literature into reality through online games and electronic games, and in a sense this eliminates the boundary between reality and the fantasy world. This makes it more attractive to young people.

\footnotetext{
${ }^{20}$ Wang Shu, Historical Motifs and Values: Survey of Online Fantasy Fiction, Theory and Creation, third issue, 2008.

21 Xu Wenjun, On “fantasy" Fiction in Online Literature, p. 8.

${ }^{22} \mathrm{Hu}$ Shi, Preface to Science and Outlook on Life, see Collected Works of Hu Shi (Volume 3), Beijing: Peking University Press, 1998, p. 152, as cited in Yang Chunshi, Modernity and Chinese Literary Trends, Beijing: SDX Joint Publishing Corporation, 2009, p. 114.
} 
Chinese fantasy literature is a kind of adolescent literature mainly focused on adolescence, and it is a fantasy literature. Its blossoming in adolescence is not without reason. "The ability to involve oneself in fantasy-related activities is part of an ongoing process that begins in childhood and continues in adolescence."23 Its main function "In this case, fantasy activities appear to serve an adaptive function, that is, a way of coping with the physical and mental pain in cases where significant failure, frustration, abuse or isolation are present. ${ }^{24}$ Fantasy literature is popular in China because it meets the demands of a young Chinese generation that has newly entered society and that suffers from a great psychological gap. It also meets the requirements of young people to redeem their egos and self-heal in fantasy.

It is worth noting that the reason Chinese fantasy literature has been able to become a trend or subculture is inseparable from two key factors. Without these, this literature could not be so influential and could not even become a mass trend. I believe that these two key factors are modern logic and modernity's liberation of human emotion. As for the first factor, "Modern logic is: the new is the good and the latest is the best, and therefore the youth are certainly better than the elderly and innovation is inevitably better than the old-fashioned."25 Modernity endows new things with natural rationality and the power of youth as priority, and under such circumstances the popularity of Chinese fantasy culture has become possible. This is because it is new and is adolescent culture, and it occupies natural rationality in modernity. As for the second factor, an important result of modernity has been its liberation of human sensibility, something we can call sensible modernity. ${ }^{26}$ To some extent, modernity is the re-shaping of human desire, ${ }^{27}$ and its significance lies in this: "If those things that are repressed, forbidden in acceptable language, and declared shameful are inseparable cultural components, they will not be abolished. They will either temporarily remain silent at the bottom of civilization in order to survive, or they seek opportunities to vent in a distorted manner of expression.,28

Therefore, Chinese fantasy literature has "priority of youth" and "new is good" as its first logic and expresses its emotion with sensibility. It deconstructs and subverts the existing cultural order with its solipsism, but due to its lack of strength it cannot completely overturn the existing social value system. It can only construct its own legitimacy through fantasy and by borrowing fragments of Western knowledge to conceal its own paucity. It is exactly this paucity that enables it to successfully use successful styles in the literary world in order to identify with the cruel reality in the literary fantasy world, achieve access to success by obedience to real logic in the fantasy world, and complete its "daydream." This literature is therefore essentially self-cathartic and symbolic and is the psychosexual "self-salvation" found by a lonely, wounded, and vulnerable soul in a fantasy world.

\section{Second, Convoluted Aesthetics: A Chinese Tragedy}

If Chinese fantasy literature is a symbol of self-catharsis in adolescence and is an aesthetic in contemporary Chinese adolescence, then this convoluted aesthetics is aesthetics in adulthood. It faces a social

\footnotetext{
${ }^{23}$ Anne L. C. Runehov, Lluis Oviedo: Encyclopedia of Sciences and Religions, New York: Springer Netherlands, 2013, p. 985.

24 Anne L. C. Runehov, Lluis Oviedo: Encyclopedia of Sciences and Religions, New York: Springer Netherlands, 2013, p. 986.

${ }^{25}$ Gan Yang, Political philosopher Strauss: Revival of classical conservative political philosophy; Leo Strauss, Natural Right and History, translated by Peng Gang, Beijing: SDX Joint Publishing Corporation, 2003, p. 10.

${ }^{26}$ See Yang Chunshi, Modernity and Chinese Literary Trends, Beijing: SDX Joint Publishing Corporation, 2009, pp. 9-10.

27 See [US] Albert Otto Hirschman, The Passions and the Interests: Political Arguments for Capitalism Before Its Triumph, translated by Feng Keli, Hangzhou: Zhejiang University Press, 2015, pp. 5-61.

${ }^{28}$ [Britain] Les Zeke Kolakowski, Metaphysical Horror, translated by Tang Shaojie and Zuo Yanxin, Beijing: SDX Joint Publishing Corporation, 1999, p. 8.
} 
dimension full of secular hardships and thinking of one's own destiny. This aesthetic is prominently reflected in "Loss", a contemporary movie directed by Zhou Xiaowen, and Monk, a novella by Chen Jiming that presents the specific aesthetic meaning of Chinese society experiencing modernity.

"Loss" describes Lily, a simple rural girl who goes to a big city to work and falls in love with Hong Kong truck driver Long Zai. She is dedicated to pure love and does not ask for any information about him and totally trusts their love. Later she becomes pregnant and looks for Long Zai, who has disappeared. She gives birth to this child who has congenital heart disease, and in order to treat her baby she needs to pay 80,000 yuan worth of medical costs in advance. She tries all kinds of ways to get the money, but because of her child she is continually dismissed and refused. The child born as a love “token” becomes her "Achilles' heel." Facing a child who can be felled by disease at any moment, where is she to go? The movie depicts three possible endings. The first involves drug trafficking for money, and she is sentenced to death. The second has her succumbing to life's pressure by marrying a wealthy old man and leading a prosperous life, rescuing her child in the process but losing the most lustrous aspect of her character. The third ending is that the child dies and she disappears into a vast crowd. Professor Wang Jie has a unique view: "Lily's image tells us that utopia is not dead in modern life; it exists in a ghostly form or shows up in 'rhymed' form in an unexpected place, touching and calling to us in the form of a tragedy.,"29

I believe the movie "Loss" presents a modern tragedy unique to China. If tragedy in terms of its Greek origin is pondering the sacred, then comedy is pondering reality. Since modernity, those things that should have been given to gods are given to humans instead as humans in the image of gods come into the world. Meanwhile it is undeniable that human existence also has a bestial dimension in addition to a divine one, as one American scholar has clearly pointed out: "A thinking clue of Enlightenment is to believe that a human is a god, and another clue is to regard a human as a beast. ${ }^{30}$ People wandering in these two sides use their own unique ways to integrate ancient Greek tragedy with comedy. If in ancient Greek tragedy people with lofty characters are inevitably destroyed in the world, the aesthetic significance of modern Chinese tragedy lies in conflicts and convolution between the cruelty brought about by modernity and the traditional virtues inherent in people when people with traditional virtues face modern society. Faced with harsh modernity, where shall we go? Shall we give up our cherished traditions, beautiful personalities, and traditional humanity or not? "Loss" reflects this loss, a loss between modernity and tradition and hovering between the modern and the traditional. The only result of trying to understand and answer one side from the standpoint and perspective of the other is modern "convoluted" aesthetics: hovering and convoluting between tradition and now, lingering between survival and existence; every time we face the reality of living and ask for help from tradition (the significance of existence), we only find complete nothingness hovering between two edges of quite opposite ideas. If we say a totally different idea is a "blade," then trying to rely on one "blade” to solve another "blade” is dangerous. It is strange that the preexistence of the real world makes it necessary for us have to hover between the two "blades," and perhaps this is the significance of modern tragedy: "Many great writers, especially modern ones, often find that comedy frequently contains tragic experience and that painful tears and laughter find a way out." ${ }^{31}$ The special

\footnotetext{
${ }^{29}$ Wang Jie, No dream, No Future: On the Aesthetic Dimensions of the "China Dream" and the Task of the Literary Critic, Beijing Forum (2014) on Civilized Harmony And Common Prosperity—China and The World: Tradition, Reality and Future: "Sinology paradigm and study on China issue" special papers and abstract book, November, 2014, p. 8.

${ }^{30}$ [US] Michelle Allen Gillespie, The Theological Origins of Modernity, translated by Zhang Butian, Changsha: Hunan Science and Technology Press, 2011, p. 358.

31 Zhou Ning, Shadow or Mirror, Xiamen: Xiamen University Press, 2015, p. 6.
} 
feature of Chinese-style tragedy is that it can combine these two blades and contain them with its special compatibility, thus making nothingness for the future look back toward the past. Hovering between tradition and modernity, the question it faces is how to move toward the future. If "Loss" poses such a question, in a sense Chen Jiming's Monk answers it.

Chen Jiming's novella Monk, formerly known as Beijing Monk, was first published in the ninth issue of People's Literature in 2011 and has since been reprinted by many domestic publications. It was subsequently published in a separate edition by Chongqing Publishing Group in 2013. In this article, I use the separate edition for convenience. Chen Jiming's Monk answers the question of how to settle down in modernity. The renunciant monk Ke Cheng (named Zhang Lei after returning to secular life) puts up at the Beijing Guanyin Temple for a stay, and when he persists in Buddhist doctrine and insists on no killing, he is continuously questioned by Hong Fang, a mortal woman: "I ... am pregnant by accident; can I have an abortion?”32 Hong Fang tells him she is from a hair salon and got pregnant while working outside. She does not know the child's father and in desperation comes to the Guanyin Temple to ask Ke Cheng for help. He responds to her by insisting on no killing, and in this way he is involved in secular life. The child is born and abandoned in the temple by Hong Fang, but she later takes the baby back. Ke Cheng's Buddhist belief in no killing results in the birth of this child, and out of love and duty for Hong Fang he summons the courage to return to secular life and lead the life of a householder in the mortal world. He is still vegetarian and still sits in meditation; in other words, he practices in the secular world. Although there is much cruelty, Zhang Lei moves from the original escape toward active confrontation: "Ke Cheng surprisingly finds that he is no longer afraid of trouble! The previous fear of trouble in the mortal world, big or small, must have been because of his youth and his lack of understanding of Buddhism, and now that is no longer the case.”33

It is an obsession and also a change. Ke Cheng becomes a monk for fear of trouble. While persistence is his true quality, when he is a monk he says, "Not even monks can succeed in treating hardships as a teacher and poverty as happiness. Can this world be saved?"34 This is after his thorough understanding of Buddhism and his realization of the contradictions in the world and in life; he does not go with the trends but believes in contradiction. According to Professor Wang Jie, "Beijing Monk is tragic because 'good people' and 'the sacred' hit up against a wall everywhere in materialistic reality and reach a peaceful and harmonious living condition in the process of 'failure' and concession. The novella tells us through metaphor that the future or the other shore is not a sacred 'eternal female’ but a 'pock-marked Guanyin' with defects and secularity.”35 Professor Wang Jie calls this China's unique "beautified loftiness": "The Chinese concept of tragedy is the result of the combination of traditional Chinese culture tragedy with tragic phenomena over the course of China's modernization, which itself is a contradictory phenomenon. Aesthetic experience of this complicated phenomenon is the realistic basis for us to continue being kind-hearted, just, and conscientious in seemingly desperate reality."36

I agree with this opinion. We should see the profound social roots that produce this Chinese-style tragedy: the particularity of Chinese modernity. Professor Yang Chunshi refers to this particularity as a conflict between

\footnotetext{
32 Chen Jiming, Monk, p. 1.

33 Chen Jiming, Monk, p. 112.

${ }^{34}$ Chen Jiming, Monk, p. 21.

${ }^{35}$ Wang Jie and Xie Zhuoting, Chinese Tragedy Concept: Theoretical Tradition and Its Contemporary Significance, Marxism Aesthetics Research, first issue.2013.

${ }^{36}$ Wang Jie and Xie Zhuoting, Chinese Tragedy Concept: Theoretical Tradition and Its Contemporary Significance, Marxism Aesthetics Research, first issue, 2013.
} 
Chinese modernity and the nation-state, one "rooted in the conflict between two tasks in China's modernization, namely the conflict between fighting for modernity and for the establishment of a modern nation-state. Since modernity comes from the West and the establishment of a modern nation-state needs to be anti-imperialist, these two are necessarily contradictory. The urgency of the national crisis, combined with the nature of 'absolutism' in the early modern nation-state, led to the establishment of the modern nation-state by scarifying modernity and anti-modernity. This is the historical basis of Salvation Overpowering Enlightenment.”37 In other words, China promotes modernity by opposing modernity, and because modernity is not compatible with native Chinese culture and because of the appearance of post-modernity, the "Protestant ethic" in which modernity is the first driving force died out with just the results. Max Weber foresaw: "As with the development model we have repeatedly observed, when the religious foundation of thought dies, utilitarian tendencies sneak in undetected and rule the roost." ${ }^{38}$ Since the advent of modernity, human society has generated huge productivity and human well-being has been greatly improved, but human beings have lost their spiritual home. This is even more obvious in China, as shown in the self-catharsis and self-healing in fantasy literature and the contradiction between the secular and the sacred in the social dimension. It reflects an intertwining of convoluted aesthetics. More importantly, this tendency does not remain solely in literary works-it enters communities and turns into reality. That is, it uses the exchange function of money to achieve or obtain self-worth.

\section{Third, Fetish Aesthetics Symbolizing Exchange}

Traditional aesthetics and commercial commodities are seldom related with fetishism. Since modern aesthetics broke out of its self-enclosed system, it has been increasingly closely linked to economic society, the inevitable result of the logic of modern cultural industry: "Sorcery becomes a pure activity and a means; in other words, it becomes an industry. The rational formal process is simply the intellectual expression of mechanized production methods. The means becomes fetishism and is added with happiness." ${ }^{\text {,9 }}$ The only difference is that science and technology exercise everything that sorcery exercises before going through rational calculation; its pursuit of happiness is simply the result of benefit maximization. Modernity leads to an atomistic society in which each individual has become an isolated atom, and protests against icy modernity use art to warm slowly numbed hearts. We can therefore say that art "is an artificial and imaginary lover; what it responds to is not demand, but love." ${ }^{40}$ It is precisely through this type of love that can we eliminate self-isolation and connect people with the world from which they were once cut off. Art is an artificial lover protecting our real existence and cutting us off from the cruelty of the world. So modern capitalism evolves into aesthetic capitalism, gains power over the world in an aesthetic manner, and obtains self-satisfaction through the shaping of taste. It is a symbolic exchange with money as the medium. Its essence is that "The symbol is not a concept, system, or category, and neither is it 'structure.' It is an exchange behavior and a social relationship. It ends and dispels reality and at the same time dispels the contradiction between reality and

\footnotetext{
37 Yang Chunshi, Two May Fourths: Conflict Between Modernity and Modern National States, Shanghai Culture, $2^{\text {nd }}$ issue, 2015.

38 [Germany] Max Weber, The Protestant Ethic and the Spirit of Capitalism, translated by Kang Le and Jian Huimei, Guilin: Guangxi Normal University Press, 2013, p. 177.

39 [Germany] Max Horkheimer and Theodor Adorno, Dialectics of Enlightenment: Philosophical Fragments, p. 91.

40 [France] Olivier Assouly. Aesthetic Capitalism: Industrialization of Taste, translated by Huang Yan, Shanghai: East China Normal University Press, 2013, p. 71.
} 
imagination ... symbolization ends this separation code and the lexical vocabulary items of separation. It is the utopia that ends soul and body, man and nature, the real and the unreal, and birth and death." ${ }^{\text {"11 }}$ It is a carefully constructed fortress against impermanence and illusion in life.

If the above analysis of Chinese fantasy literature and Chinese-style tragedy has been carried in a narrow text, this phenomenon has already spanned the distance between literature and reality and is performed in the real world. In 2015 there were two sensational and symbolic landmark events in China: First, Huang Xiaoming married Yang Ying (Angelababy) in an unprecedentedly lavish and extravagant wedding known as "the wedding of the century.” The wedding cost as much as 190 million yuan and attracted a large number of entertainment stars in a scene reminiscent of an awards party. This wedding caused a sensation abroad and attracted the attention of US media. ${ }^{42}$ The other event was that Jack Ma's painting "Peach Garden" was evaluated and sold at auction for over two million yuan. ${ }^{43}$ Jack Ma is famous in commerce, but his painting is only on the amateur level. Although the painting was co-created with the well-known artist Zeng Fanzhi, the two million yuan price tag was not arrived at through common sense.

These two events both symbolize certain fetish aesthetics. The difference between them is that Huang Xiaoming utilized the exchange function of money to achieve a dream. Huang Xiaoming said at the wedding that he simply wanted to bring the best in the world to her, while Yang Ying said she would quietly support Huang Xiaoming in life and accompany him in death because he was her dream to whom she wanted to give happiness. ${ }^{44}$ We can see their expectation for love and regard it as a most precious thing. Spending money like water on the wedding was a kind of symbolic exchange to some extent, and they hoped in this way to express how much they cherish each other. Through this wedding, they hoped to eliminate and isolate harsh reality, to make good imagination eternal, and to dispel reality with imagination, all the while trying to introduce imagination into reality and thereby establish that imagination can become reality. The heavy attention to imaginary ritual was fear for the existence of modern society. They wanted to comfort themselves through love as imaginary lovers so that they could accompany each other on the road of life, fight against the impermanence of life with love, and have the courage to confront nothingness with the mutual support of love. From a philosophical point of view, we should say that this was an escape from reality and a fight against it. This perhaps symbolizes a mental condition widespread in modern society. If love is to continuously seek for ego, marriage would be a symbol of the end. The two sides find their ego in each other and in the process obtain a better life and the courage to live, but the means for realizing this is money, the magic of money fetishism. When we confirm that love is great, we confirm fetish aesthetics, just as Adorno said: "If exchange itself is a secular sacrifice form, sacrifice will become a reasonable exchange ritual sorcery mode and a tool for human dominating over gods: the arrogation over gods is realized by observance of the gods systems. ${ }^{, 45}$ That Jack Ma's painting was auctioned off at a spectacularly high price can be said in a sense to mean that the relationship between a painting's price and its value have not been effectively reflected, and also to mean that

${ }^{41}$ [France] Jean Baudrillard, Symbolize Exchange and Death, translated by Che Jinshan, Nanjing: Yilin Press, 2012, pp. $186-187$.

${ }^{42}$ Xinhua website: "US media pay attention to Huang Xiaoming's wedding and ask surprisingly: Who is Angelababy”, retrieved 08:27 on October 30, 2015 from http://www.js.xinhuanet.com/2015-10/30/c_1116987620.htm.

43 Guangming website: “Jack Ma’s painting will be auctioned with an estimated price of 2 million”, retrieved 09:08 on October 3, 2015 from http://politics.gmw.cn/2015-10/03/content_17242360.htm

${ }^{44}$ Sina website: "Century Wedding of Huang Xiaoming Shows His Too Much Love for Baby! Shake Half of Entertainment Circle”, retrieved 6:28 on October 9, 2015 from http://ent.sina.com.cn/s/m/2015-10-09/doc-ifxirwnr6841117.shtml.

45 [Germany] Max Horkheimer and Theodor Adorno, Dialectics of Enlightenment: Philosophical Fragments, p. 41. 
the logic behind it is the realization of the way of internal logic in fetish aesthetics: "As long as money is absolute, art should be disposed at will, and then the internal structure of cultural goods gets converted and presented." 46

If we say that Chinese fantasy literature stands for adolescent ego aesthetics, what Chinese-style tragedy faces is adulthood aesthetics, and fetish aesthetics is self-imposed exile in the face of modernity to fight against modernity with art and love. These three aesthetics realize the evolution from the ego level to the social level and thence on to the realization of reality. If the first two are thinking in text, then fetish aesthetics has already entered into our reality and become its landscape, somehow completing the evolutionary process from ego to society to reality. Whether adolescent ego aesthetics and convoluted modernity aesthetics will necessarily evolve into fetishis esthetics is a question worth pondering. At the same there is the question of whether fetish aesthetics will reasonably evolve from itself into ego aesthetics and thence to convoluted aesthetics, proceeding in a repeating cycle (they will all have "children," after all). How contemporary Chinese aesthetics will answer this question is a weighty issue the times have handed us!

\footnotetext{
${ }^{46}$ [Germany] Max Horkheimer and Theodor Adorno, Dialectics of Enlightenment: Philosophical Fragments, p. 143.
} 